\title{
As Consoantes do Português Falado no Vale do Cuiabá
}

\author{
Manoel Mourivaldo SANTIAGO ALMEIDA* \\ Universidade Federal de Mato Grosso (UFMT)
}

Em 1999 publiquei em Português no Brasil: Estudos Fonéticos e Fonológicos, também organizado por Aguilera, um ensaio sobre as vogais no falar cuiabano. Como naquele texto, neste, que trato das consoantes, continuo expondo parte da análise dos corpora colhidos no Vale do Cuiabá, ou Baixada Cuiabana (como quer a voz popular), Mato Grosso, para o projeto de pesquisa Filologia Bandeirante. ${ }^{1}$

O objetivo aqui, ainda sem fazer relação com traços de uma ou mais fases do português antigo - que é o objetivo do Filologia Bandeirante -, é o de descrever o quadro das consoantes que se ouve na oralidade cuiabana.

Refiro-me ao cuiabano da "beira do rio", com pouco ou nenhum grau de instrução e, em média, na faixa etária dos cinqüenta anos, de pais e, de preferência, avós também cuiabanos ribeirinhos: o chamado "cuiabano de chapa-e-cruz", o cuiabano genuíno. Na verdade, essas variáveis não determinam o falante ideal ou perfeito representante do dialeto, porque, com freqüência, podemos encontrar as mesmas

\footnotetext{
* Professor Doutor da Universidade de São Paulo (USP) e Sócio Correspondente da Academia Brasileira de Filologia (ABF).

${ }^{1}$ Só para rememorar: Filologia Bandeirante (USP, UFMG, UFG, UFMT) apresenta a constituição de um projeto temático de equipe para coleta de material lingüístico acompanhado de estudos para identificação, análise e tabulação de traços pertencentes a uma ou mais fases anteriores da língua portuguesa, provavelmente preservados em localidades situadas nas trilhas das bandeiras paulistas de fins do século XVII, com repercussão ao longo do século XVIII. O objetivo é documentar e descrever aspectos lingüísticos do português falado na área indicada, propiciando aos estudiosos da língua um corpus cientificamente preparado para seu estudo, com a hipótese de que a língua documentada nessas regiões apresenta traços do português do tempo dos bandeirantes. A pesquisa abrange os estados de São Paulo, Minas Gerais, Goiás e Mato Grosso.
} 
características lingüísticas - comuns obviamente nos analfabetos, mais velhos e do interior - na expressão oral dos alfabetizados de qualquer faixa etária e que vivem na cidade. Principalmente se ainda não se afastaram por longos períodos do seu meio social, seja para trabalhar, ou estudar.

Para ilustrar, aproveito aqui o mesmo exemplo dado no texto sobre as vogais. Numa mesma família observamos que os filhos de até doze anos utilizam a mesma variedade lingüística de seus pais, ao passo que os acima dessa idade, que trabalham e/ou estudam a mais tempo que aqueles, só recorrem à variedade lingüística dos seus pares em situação bem familiar. Observamos também que as mulheres - até mesmo por permanecerem mais em casa do que os homens, que saem para a labuta além das fronteiras do falar local - deixam mais transparentes os traços que caracterizam o falar cuiabano.

Quanto à coleta do material lingüístico (o mesmo das vogais) utilizado neste trabalho, optamos por não empregar nenhum tipo de questionário, como é comum à pesquisa dialetológica. Os trechos analisados foram extraídos de conversas livres. Algumas delas sem a nossa participação direta. O contexto: tarde de domingo. Residência de um dos colaboradores. Amigos e familiares (re)contam histórias de vida, saboreando-as entre baforadas de cigarros de palha, acordes de viola-de-cocho ${ }^{2}$ e guaraná "relado".

$\mathrm{Na}$ volta aos informantes, como pretendemos, para futuras gravações, com a finalidade de testar algum fenômeno que interesse aos objetivos do projeto, necessariamente teremos que elaborar um questionário ou, no mínimo, seguir algum roteiro que nos possibilite dirigir a conversa para elementos pontuais.

Por fim, ressaltamos que no quadro das consoantes aqui levantado, certamente não figura todas as variações merecedoras de destaque, perceptíveis no falar cuiabano, como as articulações secundárias, sejam nas consoantes, sejam nas vogais, mas, sem dúvida,

\footnotetext{
${ }^{2}$ Instrumento musical, artesanal, semelhante ao alaúde, que acompanha os versos de manifestações culturais (canto e dança) típicas da região, como o Cururu (exclusivo para homens) e o Siriri (comungado entre homens e mulheres).
} 
é um esboço capaz de nos apresentar mais uma parte do aspecto fonético-fonológico desse falar local e, por extensão, do português falado/popular no/do Brasil. Antecipadamente, podemos dizer que, no geral, as consoantes do falar cuiabano não apresentam um grande número de disparidades em relação ao português falado em outras regiões brasileiras, européias e africanas.

Tal qual agimos na descrição das vogais, também neste exame, como não poderia deixar de ser, fizemos correlações e alusões a alguns autores que trabalharam e/ou trabalham com a descrição do português do Brasil, de Portugal ou de outros países e comunidades lusófonos.

\section{Oclusivas Surdas /p/, /t/, /k/ e Sonoras /b/, /d/, /g/}

Das consoantes oclusivas bilabiais, /p/ e /b/, a sonora /b/ apresenta estas particularidades: a) em alguns vocábulos é possível registrar a alternância de /b/ com a fricativa labiodental também sonora /v/, como ocorre, por exemplo, em [lava ' red] lavareda no lugar de labareda. b) No vocábulo também, ao lado de ocorrências em que não se registra nenhuma modificação dessa consoante [t ẽ ' bẽ̃̃], que via de regra é a forma mais freqüente, pode ocorrer casos em que o /b/, por dissimilação, sofra síncope, cedendo lugar à nasal, também sonora, $/ \mathrm{m} /$, conservando ou não o ditongo final [ $t \tilde{e}$ ' mẽ j̃], [ $t \tilde{e}$ ' mẽ].

Não se trata de fenômenos exclusivos do falar cuiabano. Eles podem ser registrados tanto em outras regiões brasileiras, quanto em falares do além-mar. A variação observada em vocábulos como vassoura/bassoura e assovio/assobio está inclusive dicionarizada. Essa alternância $b / v$, bem como a síncope do $b$ no vocábulo também são da mesma forma fatos observados por Cruz (1991, p. 73) no falar da aldeia de Odeleite, no sul de Portugal. A pesquisadora noticia ainda que a troca de $b$ por $v$, com caráter não sistemático, é registrada em muitos falares portugueses.

Quanto às alveolares ou dentais /t/ e /d/, em posição intervocálica, diferentemente de outras regiões brasileiras que tendem 
para uma realização africada palatalizada quando estão compondo sílaba com /i/, apresentam-se no falar cuiabano com articulação predominantemente oclusiva alveolodental, sem o traço fricativo final. Dentre outros exemplos: ['sعti] sete, [pa ' rẽti] parente, [' mũ jtu] muito, [' f rẽti] frente, ['dia] dia, [di 'vĩnu] divino, [vę ' dadi] verdade, [bibi 'disi] bebedice.

Essas realizações só não conseguiram uma freqüência de cem por cento das ocorrências por conta do registro de ['sit $\int u$ ] sítio, realizado por um informante descendente de nordestinos. Os avós são baianos.

Quanto às consoantes velares $/ \mathrm{k} / \mathrm{e} / \mathrm{g} /$, não registramos em todo o corpus transcrito nenhuma particularidade capaz de distinguir cada uma dessas consoantes da pronúncia comum aos falantes do português de uma maneira geral. Dentre outros exemplos temos: [kuru ' ru] cururu, [pu ' ke] porque, [i Ska ' pava] escapava, [gẽ ' za] ganzá, [kũ ' migu] comigo, [kẽe' ' goti] cangote.

\section{Nasais $/ \mathrm{m} /, / \mathrm{n} /, / \mathrm{n} /$}

Das consoantes nasais $(/ \mathrm{m} /, / \mathrm{n} /, / \mathrm{n} /)$ apresentam alterações relevantes a bilabial $/ \mathrm{m} /$ e a palatal $/ \mathrm{n} /$.

A primeira, como é comum no português falado em geral, freqüentemente deixa de ser realizada em vocábulos como uma, alguma e numa, restando da consoante apenas a nasalação da vogal /u/. Dentre muitas ocorrências: [' ũa] uma, [a⿶ ' gũa] alguma, [' nũa] numa. Com esse mesmo comportamento Penha (1997, p. 183-187) registra essa consoante na linguagem rural de São Domingos, sul de Minas Gerais.

A segunda, também como é comum no português falado, pode apresentar-se despalatalizada ou iotizada, como vemos no vocábulo minha(s), com $i$ oral ['mia], dentre outras ocorrências, ou com $i$ nasalado [' mĩa]. Além desse vocábulo registramos outros em que o fenômeno se repete: [i $\int \mathrm{to}$ ' rĩa] historinha, [' tĩa] tinha, [sĩ ' o]

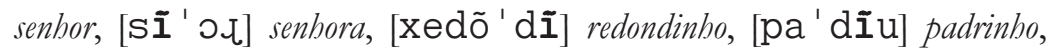
[igwa ' zĩ] igualizinho, [f $\varepsilon \int$ ' t $\left.\mathbf{i} a\right]$ festinha. A forma inalterada também foi ouvida: ['tĩna] tinha, ['mĩna] minha, [igwa 'zĩn] igualzinho, 
[sĩ'no] senhor, [sĩ' nora] senhora.

Quanto à alveolar / $\mathrm{n} /$ em todo o corpus analisado houve apenas um caso, esporádico, em que essa consoante, em posição intervocálica, deixa de ser pronunciada. Pelo menos é o que fica constatado em [fi' i ] fininho.

\section{Fricativas Surdas /f/, /s/ e Sonoras /v/, /z/}

Quanto às consoantes fricativas /f/ e / / / não registramos em todo o corpus transcrito nenhuma particularidade que possa alterar a pronúncia corriqueira de cada uma dessas consoantes. Dentre outros exemplos temos: ['f $\mathbf{e}$ ẽi] frente, [' $\mathbf{f} \varepsilon \int \mathrm{ta}$ festa, [fi $\mathrm{i}$ 'li $\left.\int\right]$ feliz; [livra ' mẽtu] livramento, [vi ' ola] viola, [f i ' kav] ficava, etc. Porém, vale retomar a informação já dada ao tratarmos da oclusiva bilabial sonora /b/, quando ressaltamos a alternância b/v.

No falar cuiabano, as alterações relevantes, nesse grupo de fricativas, ficam por conta das alveolares surda /s/ e sonora $/ \mathrm{z} /$. Trata-se da mudança do ponto de articulação, em que de alveolar /s/ passa a pré-palatal $/ S /$, principalmente quando se encontra em final de vocábulo: ['doS] dois, ['maS] mas, ['eli $\left.\int\right]$ eles, ['tre $\left.\int\right]$ três, ['kẽtuS] quantos; ['veS] ver, ['di $\left.\int\right]$ dir, ['faS] far, ['deS] der, etc.

O recuo do ponto articulatório $[\mathrm{s}]>[S]$ ainda pode ocorrer em outros contextos, como em travamento de sílaba, no interior do

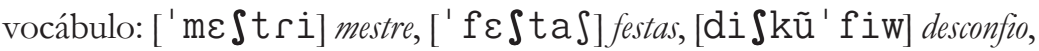

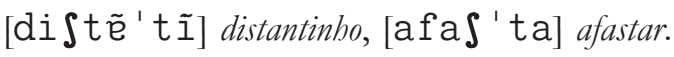

Também é possível notar essa mesma alteração fora desses dois ambientes fonéticos, como, por exemplo, em posição intervocálica: [na ' Sid] nascido, [pade ' Sẽnu] padecendo, [pi ' Siz] preciso, [pa ' S ja] passear, ['mo $\int u$ ] moço; em início de vocábulo: [ $\int \tilde{I}$ 'o] senhor e [' $S a$ ] sua, [' $\int \varepsilon_{\text {utu }}$ certo; e, ainda, em início de sílaba, quando precede uma

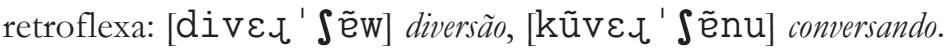

Foi registrado, ainda, um único caso em que fricativa surda /s/ passa a retroflexa: ['me ¿ma] merma por mesma. 
Isso, no entanto, não quer dizer que não haja a sibilante /s/ no quadro das consoantes do falar cuiabano. Ao lado das formas acima, coexistem, às vezes em um mesmo falante, as realizações: [ 'dos]

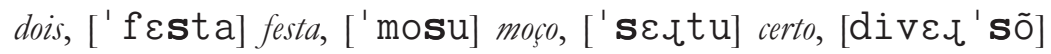
diversão; ['ves] ver, etc.

A "pronúncia chiante de s e z implosivos" (posição final de sílaba), resultando, respectivamente, [S] e [3], segundo Teyssier (1997, p. 54), é comum no português europeu. Trata-se do mesmo fenômeno observado no litoral brasileiro (Rio de Janeiro, Santos, nordeste como um todo e, ainda, Pará), que muitos acreditam ser herança da variante européia trazida pela família real e cerca de quinze mil patrícios que a acompanhava (início do século XIX). Esse fato histórico certamente colaborou para a fixação de $/ \mathrm{S} /$ e / $/$ implosivos na costa brasílica, mas prefiro acreditar na chegada dessas chiantes, aqui no Brasil, bem antes da corte, e que a presença da realeza não tenha sido a única explicação para que elas se fixassem no português brasileiro. Senão, como explicá-las tão produtivas num dialeto tão longe do mar? Há, no entanto, pelo menos uma diferença entre a pronúncia cuiabana e a do português europeu, como podemos observar nos exemplos acima.

Trata-se do contexto: enquanto no português europeu a surda / $/$ só ocorre em final absoluto ou travando sílaba, diante de uma consoante surda, no falar cuiabano, por sua vez, pode ocorrer nesse contexto europeu, bem como em posição intervocálica [ $\mathrm{moSu}$ moşo, em início de sílaba [ $\int \tilde{I}^{\prime} O$ ] senhor e depois de retroflexa

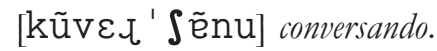

O recuo do ponto de articulação também ocorre com a sonora [z] $>$ [3], como se ouve em, no falar cuiabano a tendência é permanecer a surda $/ S /$, como fica provado em ['razga] rasga e ['vaza] várzea, convivendo ora com ['vadza], ora com ['vazja].

\section{Fricativas $/ \mathrm{S} /$ e $/ 3 /$, e africadas $/ \mathrm{t} \int /$ e $/ \mathrm{d} 3 /$}

As consoantes fricativas pré-palatais surda / $/$ / e sonora /3/, no falar cuiabano, comumente são pronunciadas, respectivamente, 
como africadas surda / t $\int /$ e sonora /dz/: [t $\int e$ ' ga] chegar, ['t $\left.\int a\right]$ chá, [' bat Su] baixo, ['kot $\left.\int u\right]$ cocho, [mit $\int$ i s i ' keru] mexeriqueiro, ['putsa] puxa, ['petsi] peixe, [de't $\mathrm{t}$ ava] deixava, [t Suva ' rada] chuvarada; [' lõdzi] longe, ['dzẽti] gente, ['dza] já, [ro ' dadzi] rodagem, [a 'dzuda] ajuda, [' odzi] hoje, [ĩ ' dzẽẽjnu] engenho, [' dzũtu] junto, ['dzõ]joão, [t r ẽpulĩ ' nadzi] trampolinagem.

As realizações dessas africadas $(/ \mathrm{t} S /, / \mathrm{d} 3 /)$ no lugar das fricativas $(/ S /, / 3 /)$ são mais freqüentes na fala dos menos estudados, independente até de faixa etária. ${ }^{3}$ Numa conversa sobre festa de santo, um garoto de quatorze anos, que participava da entrevista

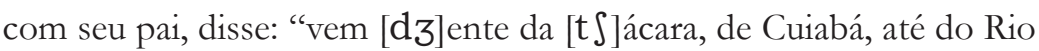
de [d3]aneiro".

Já aqueles que possuem maior grau de formação escolar, mantêm contato com variantes lingüísticas díspares da cuiabana e, principalmente, com menos de quarenta anos de idade, em média, somente recorrem a tais fonemas em contextos bem específicos, envolvendo familiares, amigos, colegas ou em manifestações culturais. Um exemplo foi o que ocorreu durante um almoço entre amigos e colegas de trabalho e de profissão (no total havia sete comensais, dentre eles (nós) três cuiabanos com curso superior, sendo dois deles doutores e professores universitários). A conversa girava em torno do trabalho e, de vez em vez, da peixada que estávamos degustando. Foi num desses de vez em vez que um dos professores cuiabanos, relaxou e, de propósito, exclamou: "que pe [t $\left.\int\right]$ ada saboroso". Foi o suficiente para que os demais cuiabanos e quase-cuiabanos entrassem no clima chapae-cruzense.

Há, no entanto, quem, a todo custo, policiando-se ao extremo, tente dissimular esses traços. Foi o que ocorreu com uma das entrevistadas. Por cultivar um preconceito estigmatizante da variante local, muitas vezes comum até na escola, a entrevistada não concordou em dizer que os cuiabanos "de primeira" pronunciem [t $\left.\int\right]$ e [dz].

\footnotetext{
${ }^{3}$ Sobre o tema foi feito um trabalho sob a ótica da sociolingüística da colega Maria Luíza Canavarros Palma, intitulado Variação fonológica na fala de Mato Grosso: um estudo sociolingüistico, publicado em 1984.
} 
Quando, em determinado momento, foi mencionado que ela não deixa transparecer os traços característicos do falar cuiabano, expressando certo orgulho, disse:

(...) pois é, todo mundo dĩ assim mesmo: que eu não pareço ser cuiabana mas eu sou cuiabana! Mas os cuiabanos mesmo... porque você sabe que o cuiabano que é de primeira... vou dizerer assim que é discurso muitos tempo... falam direito. Agora os que não fala são muita gente que vinha assim... porque veio muita gente toda parte aqui pra Cuiabá. Então ficou... por exemplo Livramento, papa banana né? Ali que eles falam... a gente conhece logo que é papa banana... bem carregado! Pessoal de Livramento, Várzea Grande mesmo já tem uma porção de coisinha esquisita... depois vem vindo os outros que são até os caipira que vem lá do sítio, de toda parte. Porque eu me lembro de minha turma, a turma de Ieda, era turma de gente que todos falavam direitinho, não tinha nada de, de 'tchá', de 'tchu', né?

E assim foi. Depois de vinte minutos de gravação a entrevistada esqueceu-se do gravador e deixou escapar "uma porção de coisinha esquisita”. Dela ouvimos: “(...) a de hoje então... já compretô de ontem de ho[d3] e (...)" e "(...) devia ter um certo estudo pra [t $\left.\int\right]$ egar ser polícia (...)".

O fato de as africadas serem tão comuns em todo o Vale Cuiabano, não quer dizer que as fricativas tenham sido totalmente apagadas do paradigma das consoantes dessa variante portuguesa. Registramos na fala até de um mesmo informante a coexistência das duas formas, num mesmo vocábulo, como, por exemplo: chegar [Se ' ga] ao lado de [t $\left.\int e^{\prime} g a\right]$, deixa [' $\operatorname{de} \int \mathrm{a}$ ] ao lado de ['det $\int \mathrm{a}$ ], e gente [' 3 ẽti] ao lado de ['dzẽti]. Dos exemplos acima, com africada, encontramos em todo o corpus transcrito as seguintes formas com fricativa: [' ba $\int u$ ] baixo, [pu 'Sa] puxar, ['de $\int \mathrm{a}$ ] deixa, [Su 'via] chovia; [' 1õzi] longe, ['3a] já, e ['o3i] hoje. 
As africadas $/ \mathrm{t} \int / \mathrm{e} / \mathrm{d} 3 /$ no lugar das fricativas $/ \mathrm{S} / \mathrm{e} /$ 3/ que pareciam exclusivas do falar cuiabano, também já foram ouvidas pelos colegas do projeto em terras paulistas. O que não é de se admirar. Amaral (1976:48) já as havia registrado no início do século passado. No mínimo, trata-se de um traço remanescente daquele "dialeto caipira" descrito por ele. A história da Língua Portuguesa também registra essas africadas em território português. Especialmente "em grande parte das províncias do Norte" (Teyssier, 1997:53).

\section{Laterais $/ 1 /, / \Lambda /$}

Só não percebemos algum tipo alteração da consoante lateral alveolar /1/ em ataque de sílaba: [' ladu] lado e ['eli] ele, ['lẽbru] lembro e [fẽe'milja] familia, [livra 'mẽtu] livramento e [pẽ ' nela] panela, etc.

Nos grupos consonantais /pl/, /bl/, /tl/, /kl/, /gl/, em todo o corpus transcrito, em todas as ocorrências da aveolar ocorre rotacismo, $[\Gamma]$ no lugar de [1], outro fenômeno facilmente observado em outras regiões brasileira: [kõpre'tej] completei, [kũpre'to] completou, [t Exaprẽ j'nazi] terraplanagem, ['dupra] dupla, ['sĩpri] simples, [kũprika 'sẽ] complicação, ['prẽta] planta, [prẽ 'to] plantou, [asẽ ' breja] assembléia, [a 't $\mathbf{r} \varepsilon \mathrm{ta}$ ] atleta, [krari ' o] clareou, [' krubi] clube, [ĩkru ' ziv] inclusive, [' greba] gleba, etc.

Travando sílaba ou em final de vocábulo, a tendência é

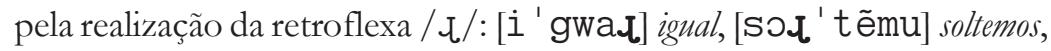
[au' gũa] alguma, [si 'nau] sinal, ['mau] mal, ['tau] tal,

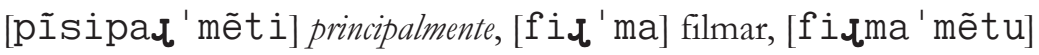
filmamento, [aıgudu 'ĩ] algodoim, [peso 'al] pessoal, [sol'tav]

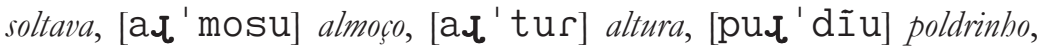
[saıva 'do] salvador, etc.

Nesse mesmo contexto o mais comum, no português brasileiro, é ocorrer a iotização da alveolar /1/, como esporadicamente também registramos no falar cuiabano: [ku ' xaw] curral e [manu ' aw] manual. 
Ainda notamos, nesse contexto, o apagamento dessa alveolar: [pesu 'a] pessoal, [a 'f redu] alfredo, [i 'gwa] igual, [igwa 'zin] igualizinho, [peso 'a] pessoal, [ku 'xa] curral, [' fasi] fácil, [di ' fisi] difícil, [ẽni ' ma] animal, [pu ' t $\mathrm{r}$ İ] poldrinho.

A alteração que a consoante lateral palatal $/ K /$ apresenta no português falado na Baixada não é diferente da observada no português popular do Brasil em geral, com tendência à iotização ou despalatalização $[K]>[\mathbf{j}]$ ou [i]: [oj ' ẽnu] olhando, [t $r$ ba' $\mathbf{j}$ a] trabalhar, [masa'via] maravilha, ['vej] velho, [t raba' java] trabalhava, [mu ' $\mathbf{j} \varepsilon]$ mulher, [mo' $\mathbf{j}$ adu] molhado.

Muitas, porém, são as ocorrências em que a lateral $/ \Lambda /$ não sofre alteração: [xiku ' $\mathbf{\Lambda}$ ia] recolbia, [t $\varsigma$ a ' ba $\mathbf{\Lambda}$ ] trabalho, [mara 'vi $\mathbf{\Lambda}$ a] maravilha, [' fi $\mathbf{\Lambda u}$ ] filho, [' mi $\mathbf{\Lambda u}$ ] milho, [mo ' $\mathbf{S a d u}]$ molhado.

\section{Vibrante /R/}

Neste item vamos incluir as realizações da vibrante $/ R /$, representadas na escrita pelos grafemas $<\mathrm{r}>\mathrm{e}<\mathrm{rr}>$, ou seja, a vibrante (múltipla) alveolar $/ \mathrm{r} /$, a tap (vibrante simples) alveolar $/ \mathrm{\Gamma} /$, a fricativa velar $/ \mathrm{x} / \mathrm{e}$ a retroflexa $/ \succsim /$.

A vibrante / R/ em posição intervocálica ou seguindo consoante na mesma sílaba tem tendência a ser pronunciando como tap, ou vibrante simples: [' ora] hora, [se ' tẽbru] setembro, [' $\varepsilon \mathbf{r a}]$ era, [kate 'd $\mathbf{\mathrm { a } a \mathrm { w }}$ ] catedral, [' fora] fora, [' sẽpri] sempre, [brĩka ' dera] brincadeira, [si $\mathbf{i}$ ' $\mathbf{r}$ ] siriri, [' f $\mathbf{r e ̃ t} i]$ frente, etc.

No entanto pode ocorre síncope desse fonema principalmente nos encontros consonantais em sílaba átona, como observamos em ['ota] outra e ['otu] outro, [kũ 'padi] compadre, dentre outras ocorrências.

Quando temos / R/ em início de vocábulo, ou em posição intervocálica, grafado com $<\mathrm{rr}>$, a tendência geral no falar cuiabano é realizar a vibrante múltipla: [rapazi ' ada] rapaz̧iada, [' rẽmu] ramo, [riuni 'õ] reunião, ['rosa] roça, [' redi] rede, [raS 'ga] rasgar, 
[ra ' pa S] rapaz, [ko ' re] correr, [gi ' tar a] guitarra, [e ' rada] errada, [ka ' rosa] carroça, [' buru] burro, [ku ' ra] curral, etc.

Em qualquer dos ambientes destacados acima pode ocorrer também a realização da fricativa velar. As formas $/ \mathrm{r} / \mathrm{e} / \mathrm{x} /$ podem coexistir até mesmo em um mesmo falante e mesmo vocábulo. Dentre outras ocorrências: [xapazi ' ada] rapaziada, ['xosa] roça, [ku 'xa] curral, [ka 'xosa] carroça, [' buxu] burro, [xe ' dõna] redona, [xaj' ga] rasgar, etc.

Quando temos /R/ em final de sílaba travada, a tendência é a realização da retroflexa, como se pode observar no chamado dialeto

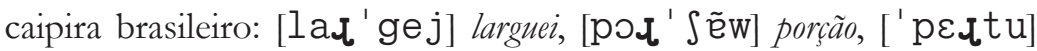

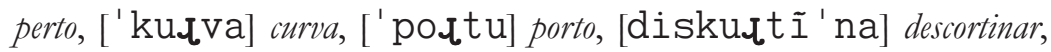
[kaðpĩta ' ria] carpintaria, [puı 'ke] porque, etc. Há ainda, nesse mesmo contexto, casos em que ocorre síncope dessa consoante: [pu 'ke] porque, [di Skutĩ 'na] descortinar.

A retroflexa, embora com pouco freqüência, também pode ocorrer em posição intervocálica: [a 'gつ」a] agora, [' foむa] fora, ['noџl] nora.

Quando temos / R/ em final de vocábulo, a tendência é ocorrer o apagamento da consoante: [fa' ze] fazer, [ka' za] casar, [ki ' ze] quiser, [pra ' ze] prazer, [mu ' $\Lambda \varepsilon]$ mulher, [gra 'va] gravar, [mu 'e] moer, etc. A freqüência desse fenômeno não chega a atingir cem por cento das ocorrências. Dependendo da velocidade com que se fala, se mais lenta, surge nesse contexto a retroflexa: [lu 'gau] lugar, [toria'dol] touriador, [sĩ' nol] senhor, [ĩkõ't rad] encontrar, [fa'lau] falar, [kẽe'tau] cantar.

Ainda é possível registrar, esporadicamente, a iotização da vibrante travando sílaba: [si w'visu] serviço.

\section{Fenômenos gerais}

Dos fenômenos gerais interessa destacar algumas ocorrências mais relevantes.

a) Acréscimo de fonema no início de vocábulo, ou prótese:

[a'lẽbru] alembro no lugar de lembro; [alẽ 'bra] alembrar no lugar de lembrar, 
b) Acréscimo de fonema do final de vocábulo, ou paragoge: ['vezi] veze no lugar de vez, [' mezi] mese no lugar de mês, etc.;

c) Apagamento de fonema no início de vocábulo, ou aférese: [r $\tilde{e}^{\prime} \mathrm{k} \tilde{\mathrm{e} n u}$ ] rancano no lugar de arrancando, [xaS ' tẽmu] rastemos no lugar de arrastamos, [sẽ ' dẽmu] cendemos no lugar de acendemos, [' mi_di] mirde no lugar de humilde, [trave'sa] travessá no lugar de atravessar, etc.;

d) Apagamento de fonema no interior de vocábulo, ou síncope: [tẽti 'ẽnu] tenteano no lugar de tenteando, e demais ocorrências do gerúndio, [' mẽma] mema no lugar de mesma, [pi ' $\mathrm{iz}$ ] peciso no lugar de preciso, [a ' f redu] afredo no lugar de alfredo, etc.;

e) Apagamento de fonema(s) no final de vocábulo, ou apócope: [ra ' ga] rasgá no lugar de rasgar, [ko ' re] corrê no lugar de correr, [i ' gwa] iguá no lugar de igual, [ku ' xa] currá no lugar de curral, etc.;

f) Transposição de fonemas, ou metátese: [t remĩ ' na] treminá no lugar de terminar,

h) Dos fenômenos envolvendo a transmutação de fonemas, destacamos:

h.1) A palatalização do /s/ em diversos contextos: travando sílaba [' $\left.m \varepsilon \int t r i\right]$ mestre, [' $\left.\mathrm{f} \varepsilon \int \mathrm{ta} \int\right]$ festas, [di Skũ ' fiw] desconfio, [a faS 'ta] afastar, em início ou final de vocábulo [ $\left.\int \tilde{I}^{\prime} \mathrm{O}\right]$ senhor, [' $\left.\int \mathrm{a}\right]$ sua, [ $\left.\int \varepsilon \_t u\right]$ certo e [de ' po $\left.\int\right]$ depois; em início de sílaba,

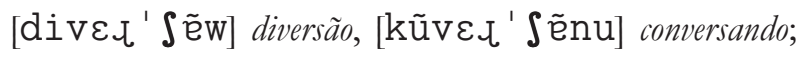
e em posição intervocálica [na 'Sid] nascido, [pade ' Sẽnu] padecendo, [pa ' $\mathrm{Jja}$ ] passear, [' mo $\left.\int \mathrm{u}\right]$ moco;

h.2) Pelo alto número de ocorrência e por serem bem característicos no falar cuiabano, embora não sejam exclusivos dessa região, merecem destaque os 
fenômenos da africatização de / $/ \mathrm{e} / 3 /$ : ['put $\left.\int a\right]$ puxa, ['pet $\left.\int \mathrm{i}\right]$ peixe, [de't $\mathrm{t}$ ava] deixava, [t Suva ' rada] chuvarada [' lõdzi] longe, ['dzẽti] gente, ['dza] já, [ro' dadzi] rodagem e do rotacismo, tanto com a vibrante simples / $\mathrm{r} /:$ ['dupra] dupla, [asẽ ' b $r \varepsilon \mathrm{ja}$ ] assembléia, [a't $\mathbf{\varepsilon} \mathrm{ta}$ ] atleta, ['krubi] clube, ['greba] gleba, quanto com a

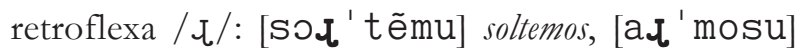
almoso, [a⿶' tur] altura, [si 'naı] sinal, [' maı] mal, [saıva ' do] salvador, dentre muitos outros exemplos

Para encerrar, vou repetir o final do texto sobre as vogais, dando algumas informações geográficas e históricas sobre a região estudada. O Vale do Cuiabá, ou Baixada Cuiabana, compreende toda a região ribeirinha, cujo alcance geográfico inclui a capital do Estado de Mato Grosso, Cuiabá, municípios e vilarejos adjacentes que devem sua origem ao rio Cuiabá e seus afluentes.

As águas destes rios foram utilizadas, principalmente, pelos monçoeiros (que se utilizam de caminhos fluviais) e bandeirantes paulistas, no século XVIII, como principal caminho de acesso, primeiramente, às aldeias indígenas (minas de escravos) e, depois, às minas auríferas dessa região.

Essas expedições mercantis foram responsáveis pela expansão do território brasileiro rumo ao oeste e fizeram com que os paulistas pisassem terras mato-grossenses. Terras que só foram consideradas importantes depois da descoberta do ouro abundante. ${ }^{4} \mathrm{~A}$ partir de então, de todos os recantos do Brasil, mormente de São Paulo,

\footnotetext{
${ }^{4}$ As bandeiras paulistas foram organizadas, no início, com a finalidade de caçar índios para serem vendidos como mão-de-obra escrava. Esta atividade se justificou porque em São Paulo, antiga Capitania de São Vicente, a produção de cana-de-açúcar, principal fonte de riqueza para a coroa portuguesa antes da mineração, não teve os êxitos alcançados no nordeste brasileiro. Então os são-vicentinos migraram do litoral para o planalto e se empenharam na atividade bandeirante. Em 1719, a Bandeira comandada por Pascoal Moreira Cabral, acidentalmente, encontrou ouro nas margens e barrancas do rio Coxipó, afluente do Cuiabá, e logo lavrou uma ata de fundação para garantir o direito de posse. Cf. Siqueira; Costa; Carvalho (1990, p. 11-13) e Holanda (1990, p. 43-73).
} 
partiram rumo ao Cuyabá "caipiras, crioulos, caboclos, sertanejos e sulinos" (RIBEIRO, 1995, p. 269-444). A maioria percorrendo caminhos essencialmente fluviais, com início no rio Anhembi (Tietê) e fim no rio Cuiabá.

$\mathrm{Na}$ rota destas expedições foram surgindo, com as minas de ouro, muitos vilarejos, que com o fim do ciclo da mineração e abolição da escravatura, insulados, permaneceram com suas características, passando de pai para filho: os costumes, as manifestações culturais e religiosas e, conseqüentemente, a variante lingüística de então, ou pelo menos alguns dos traços daquela variante portuguesa. Provar a sobrevivência desses traços é o objetivo do projeto Filologia Bandeirante, que, por extensão, apresentará um seleto material, seja da modalidade escrita, seja da falada, que certamente trará contribuições à lingüística histórica e a dialetologia.

\section{Referências bibliográficas}

AMARAL, Amadeu. O dialeto caipira. São Paulo: HUCITEC-SCETCEC, 1976.

COHEN, Maria Antonieta Amarante de Mendonça et al. Filologia bandeirante. Filologia e lingüística portuguesa, n. 1, p. 79-94, fev. 1997.

CRUZ, Maria Luisa Segura da. O falar de Odeleite. Lisboa: INIC/ CLUL, 1991.

HOLANDA, Sérgio Buarque de. Monções. São Paulo: Brasiliense, 1990.

NUNES, José Joaquim. Dialectos algarvios. Revista Lusitana, n. VII, p. 33-55, 1902.

RIBEIRO, Darcy. O povo brasileiro - a formação e sentido do Brasil.

São Paulo: Companhia das Letras, 1995. 
SILVA, B. Lopes da. Dialecto crioulo de Cabo Verde. Lisboa: Imprensa Nacional, 1957.

SANTIAGO-ALMEIDA, Manoel Mourivaldo. As vogais do português falado no Vale do Cuiabá. In: AGUILERA, Vanderci de Andrade (Org.). Português no Brasil: estudos fonéticos e fonológicos. Londrina: Ed. UEL, 1999. p. 109-124.

SILVA NETO, Serafim da. A língua portuguesa no Brasil. Lisboa, 1960.

SIQUEIRA, Elizabeth Madureira et al. O processo histórico de Mato Grosso. Cuiabá: Guaicurus, 1990.

VASCONCELOS, José Leite de. Dialectos algarvios. Revista Lusitana, n. IV, p. 324-338, 1901.

Esquisse d'une dialectologie portugaise. Paris: Aillaud e Cie., 1901.

Filologia barranquenha - apontamentos para o seu estudo. Lisboa: Imprensa Nacional/Casa da Moeda, 1955. 